\title{
Evaluation of a genetically modified foot-and-mouth disease virus vaccine candidate generated by reverse genetics
}

\author{
Pinghua Li, Xingwen Bai, Pu Sun, Dong Li, Zengjun Lu, Yimei Cao, Yuanfang Fu, Huifang Bao, Yingli Chen, \\ Baoxia Xie and Zaixin Liu*
}

\begin{abstract}
Background: Foot-and-mouth disease (FMD) is the most economically important and highly contagious disease of cloven-hoofed animals worldwide. Control of the disease has been mainly based on large-scale vaccinations with whole-virus inactivated vaccines. In recent years, a series of outbreaks of type O FMD occurred in China (including Chinese Taipei, Chinese Hong Kong) posed a tremendous threat to Chinese animal husbandry. Its causative agent, type O FMDV, has evolved into three topotypes (East-South Asia (ME-SA), Southeast Asia (SEA), Cathay (CHY)) in these regions, which represents an important obstacle to disease control. The available FMD vaccine in China shows generally good protection against ME-SA and SEA topotype viruses infection, but affords insufficient protection against some variants of the CHY topotype. Therefore, the choice of a new vaccine strain is of fundamental importance.
\end{abstract}

Results: The present study describes the generation of a full-length infectious CDNA clone of FMDV vaccine strain and a genetically modified virus with some amino acid substitutions in antigenic sites 1, 3, and 4, based on the established infectious clone. The recombinant viruses had similar growth properties to the wild O/HN/CHA/93 virus. All swine immunized with inactivated vaccine prepared from the O/HN/CHA/93 were fully protected from challenge with the viruses of ME-SA and SEA topotypes and partially protected against challenge with the virus of $\mathrm{CHY}$ topotype at 28 days post-immunization. In contrast, the swine inoculated with the genetically modified vaccine were completely protected from the infection of viruses of the three topotypes.

Conclusions: Some amino acid substitutions in the FMDV vaccine strain genome did not have an effect on the ability of viral replication in vitro. The vaccine prepared from genetically modified FMDV by reverse genetics significantly improved the protective efficacy to the variant of the $\mathrm{CHY}$ topotype, compared with the wild O/HN/ CHA/93 virus. Thus, the full-length cDNA clone of FMDV can be a useful tool to develop genetically engineered FMDV vaccine candidates to help control porcinophilic FMD epidemics in China.

\section{Background}

Foot-and-mouth disease (FMD) is a highly contagious vesicular disease of domestic and wild cloven-hooved animal species, which is caused by the foot-and-mouth disease virus (FMDV), the prototype member of the genus Aphthovirus of the family Picornaviridae. The highly contagious nature of FMDV and the associated

\footnotetext{
* Correspondence: liuzaixin3@hotmail.com

State Key Laboratory of Veterinary Etiological Biology, National Foot and Mouth Disease Reference Laboratory, Key Laboratory of Animal Virology of Ministry of Agriculture, Lanzhou Veterinary Research Institute, Chinese Academy of Agricultural Sciences, Lanzhou 730046 Gansu, China
}

high morbidity and productivity losses make it one of the most important barriers to the world trade of live animals and animal products. Control of the disease has been based on large-scale vaccinations with whole-virus inactivated vaccines, limitation of animal movements and destruction of herds exposed to the virus [1,2]. The currently available vaccine shows generally good protection against infection with the homologous and antigenically related viruses. However, difficulties facing the eradication of FMD include the antigenic diversity of FMDV in nature, which has been reflected in the identification of seven serotypes (A, O, C, SAT1, SAT2, SAT3 
and Asia1) [3] and multitudes of antigenic variants that often co-circulate in a given geographical area [4]. The emergence of antigenically novel viruses, against which existing vaccines do not provide adequate protection, may require the selection of new vaccine strains to control the viruses circulating in the field.

The FMD virion consists of a single-stranded RNA genome packaged in an icosahedrally symmetric protein shell, which is composed of 60 copies each of four structural proteins 1A (VP4), 1B (VP2), $1 \mathrm{C}$ (VP3) and 1D (VP1) [5]. Three of these proteins, VP1, VP2 and VP3, contribute to the formation of five known antigenic sites of type O FMDV [6,7]. The G-H loop and carboxy terminus of VP1 contribute to site 1, key residues have been shown to be 144, 148, 154 and 208, respectively. Amino acids at positions 31, 70-73, 75 and 77 of VP2 contribute to site 2 . Site 3 involves the B-C loop of VP1, in which key residues have been shown to be 43 to 48 [6]. Only one critical residue, at position 58 of VP3, has been identified for site 4 . Site 5 maps to a single residue (residue 149) on the G-H loop of VP1 that is distinct from site 1 . While much of the antibody response to FMDV can be directed at the G-H loop of VP1, all of the sites appear to be necessary for a complete immunologic response to either infection or vaccination $[8,9]$.

Among the seven serotypes of FMDV, serotype $O$ is prevalent in China (including Chinese Taipei, Chinese Hong Kong) and its surrounding countries [10-13]. Recent studies have showed that type O FMDV in these region were clustered into three topotypes, namely Middle East-South Asia (ME-SA), Southeast Asia (SEA), and Cathay $(\mathrm{CHY})[13,14]$. An inactivated FMD vaccine prepared from $\mathrm{O} / \mathrm{HN} / \mathrm{CHA} / 93$ strain that belongs to the CHY topotype [15], is currently available in China. This vaccine is used to protect against type $O$ FMD epidemics, which often provides complete protection against ME-SA and SEA topotype virus infection, but can't affords good protection against some variants of the CHY topotype. Therefore, the development of new vaccine strains is of urgently needed. However, the development of useful cell-culture-adapted vaccine strains from field isolates is time-consuming and expensive, limiting the availability of custom-made vaccine strains [16]. The recent progress in animal RNA virus vaccine development, particularly the reverse genetics system-based for vaccine development [17-21], provided a perspective on potential novel strategies and approaches to develop a virus vaccine candidate.

The present study describes the generation of an infectious cDNA clone of FMDV O/HN/CHA/93 vaccine strain and a genetically modified virus with some amino acid substitutions in antigenic site 1 (VP1 $134 \mathrm{C} \rightarrow \mathrm{S}, 137$ $\mathrm{S} \rightarrow \mathrm{G}, 139 \mathrm{~A} \rightarrow \mathrm{T}, 140 \mathrm{R} \rightarrow \mathrm{S}, 142 \mathrm{~V} \rightarrow \mathrm{T}, 142 \mathrm{~S} \rightarrow \mathrm{N})$, site $3(\mathrm{VP} 143 \mathrm{~T} \rightarrow \mathrm{K}, 48 \mathrm{I} \rightarrow \mathrm{V})$, and site $4(\mathrm{VP} 358 \mathrm{E} \rightarrow \mathrm{D})$, based on the established infectious clone. The replication kinetics in vitro of the recombinant viruses and the protective efficacy of inactivated oil-emulsified vaccines prepared from the genetically modified virus and the wild $\mathrm{O} / \mathrm{HN} / \mathrm{CHA} / 93$ virus against isolates of three topotypes were evaluated.

\section{Methods}

Analysis of amino acid variation of isolates of CHY topotype

The P1 or VP1 sequence data of 18 FMD reference isolates were obtained from GenBank. O/HN/CHA/93 shared high homology with O/GD/China/86 (GenBank AJ131468) [22]. The deduced amino acid sequence alignments were prepared using the data for each FMDV using SeqMan II (DNAStar Lasergene 8.0). In brief, the amino acid sequences of P1 or VP1 were maximally aligned using the MegAlign program. All the reference isolates were clustered into the CHY topotype [11,12,23-25]. Table 1 shows the origin of all reference isolates characterized in the present study and Figure 1 shows the analysis of amino acid sequences of vaccine strain and reference strains.

\section{Cell lines, viruses}

Baby hamster kidney cell (BHK-21) [26] was maintained in Dulbecco's Modified Eagle Medium (DMEM)

\begin{tabular}{|c|c|c|c|c|}
\hline Isolate & $\begin{array}{l}\text { GenBank } \\
\text { accession no. }\end{array}$ & Species & $\begin{array}{l}\text { Place } \\
\text { isolated }\end{array}$ & $\begin{array}{l}\text { Date } \\
\text { collected }\end{array}$ \\
\hline $\mathrm{O} / \mathrm{HN} / \mathrm{CHA} / 93$ & AJ131468 & Porcine & HeNan & 1993 \\
\hline O/Chu-pei/TAW/97 & AF026168 & Porcine & Taiwan & 1997 \\
\hline O/HKN/2002 & AY317098 & Porcine & Hong Kong & 2002 \\
\hline O/Tau-Yuan/TAW/97 & AF154271 & Porcine & Taiwan & 1997 \\
\hline O/Yun/TAW/97 & AF308157 & Porcine & Taiwan & 1997 \\
\hline $\begin{array}{l}\text { O/Peng-Hu/TAW/ } \\
\text { 108/99 }\end{array}$ & AY593833 & $?$ & Taiwan & 1999 \\
\hline otaiwan97 iso106/112 & AY593835 & $?$ & Taiwan & 1997 \\
\hline O/ES/2001 & AY686687 & $?$ & $?$ & 2001 \\
\hline $\mathrm{O} / \mathrm{lz}$ & DQ248888 & $?$ & $?$ & $?$ \\
\hline O/WFL & EF175732 & $?$ & $?$ & $?$ \\
\hline $\mathrm{O} / \mathrm{HK} / 2001$ & EU400597 & Porcine & Hong Kong & 2001 \\
\hline O-TW-257-2009 & GQ292739 & Porcine & Taiwan & 2009 \\
\hline O-TW-258-2009 & GQ292740 & Porcine & Taiwan & 2009 \\
\hline O/HKN/8/2004 & DQ164885 & Porcine & Hong Kong & 2004 \\
\hline O/HKN/11/2004 & DQ164888 & Porcine & Hong Kong & 2004 \\
\hline O/HKN/2/2003 & DQ164879 & Porcine & Hong Kong & 2003 \\
\hline O/HKN/1/99 & AJ294925 & Porcine & Hong Kong & 1999 \\
\hline O-TW-256-2001 & GQ292738 & Porcine & Taiwan & 2001 \\
\hline O/PEN/TAW/4/99 & AJ294928 & Porcine & Taiwan & 2001 \\
\hline
\end{tabular}

Question mark (?) indicates that data are absent. 
supplemented with $10 \%$ fetal calf serum (FBS). BSR-T7/5 cells (a BHK derivative that stably expresses T7 RNA polymerase) [27], were maintained in Glasgow Minimal Essential Medium (GMEM) supplemented with 4\% tryptose phosphate broth, $10 \% \mathrm{FBS}$, and in alternate passages geneticin was added to $1 \mathrm{mg} / \mathrm{ml}$ to ensure maintenance of the T7 polymerase gene.

FMDV O/HN/CHA/93 vaccine strain was used to construct the infectious clone and genetically modified mutant. O/HN/CHA/93 was adapted to grow in BHK cells for use in preparation of an inactivated vaccine to help control type O FMD epidemics in China. The O/Tibet/CHA/99, $\mathrm{O} / \mathrm{TAW} / \mathrm{TL} / 97$, and $\mathrm{O} / \mathrm{JX} / \mathrm{CHA} / 2010$ viruses used in the present study were obtained from the National FMD Reference Laboratory at Lanzhou Veterinary Research Institute. The O/Tibet/CHA/99 strain is of the ME-SA topotype [24], the O/TAW/TL/97 strain is of the CHY topotype [24], whereas the $\mathrm{O} / \mathrm{JX} / \mathrm{CHA} / 2010$ strain was originally isolated in China in 2010 and is of the SEA topotype [28]. Three viruses were titrated in BHK-21 cells.

\section{Construction of genome-length CDNA clone of $\mathrm{O} / \mathrm{HN}$ / $\mathrm{CHA} / 93$ vaccine strain}

All the molecular constructs were prepared by using standard molecular biological techniques [29]. Total RNAs were extracted from the virus stock of $\mathrm{O} / \mathrm{HN} /$ CHA/93 using RNeasy mini kit (Qiagen). Viral cDNAs were performed using M-MLV reverse transcriptase (Invitrogen) and specific RT primers. Four overlapping cDNA fragments (designated Z1-Z4 (Figure 2)), representing the entire viral RNA genome, were amplified by $\mathrm{PCR}$ using primer sets $\mathrm{Z} 1 / \mathrm{Z1}^{\prime}, \mathrm{Z} 2 / \mathrm{Z2}^{\prime}, \mathrm{Z} 3 / \mathrm{Z3}^{\prime}$ and $\mathrm{Z} 4 / \mathrm{Z} 4$ ', respectively. Table 2 lists the primers used to perform RT-PCR for preparation of full-length cDNA clones of $\mathrm{O} / \mathrm{HN} / \mathrm{CHA} / 93$ virus. The $\mathrm{Z} 1$ primer contains a Spe I site, T7 promoter sequence and three nonviral G residues at the $5^{\prime}$ end of the FMDV genome, the Z4' primer was engineered to add a Not I site following the viral poly(A) tail sequence. The PCRs were carried out using PrimeSTAR HS DNA Polymerase (Takara) to enhance the fidelity during the DNA synthesis. The Z1 and $Z 2$ fragments were then fused by a second round of PCR with primers $Z 1$ and $Z 2^{\prime}$ to generate Z12 fragment. Subsequently, the resulting amplicons was ligated into the pMD-20 vector, leading to the positive clone pMDZ12. The other two PCR products ( $\mathrm{Z3}$ and Z4) were separately cloned into the corresponding site of $M$ pSK vector [30], which is a derivative of pBluescriptSK (+) vector by removing T7 promoter sequence and modifying some restriction enzyme sites. The resulting positive plasmids were designated pSK-Z3 and pSK-Z4, respectively. Quick-Change ${ }^{\circledR}$ Multi Site-Directed Mutagenesis Kit (Stratagene) was used to introduce two silent mutations (GCG (Ala)-GCC (Ala), ATC (Ile)-ATA (Ile)) into Z3 segment to eliminate Not I (nucleotide position 2980) and one of $B g l$ II sites (nucleotide position 4233) (Figure 2), which will be as genetic tags by PCR amplification of the parental plasmid pSK-Z3 using Ztu1/Ztu1' and Ztu2/Ztu2' primer pairs, respectively. The modified plasmid named pSK-Z3M, was confirmed by complete DNA sequencing.

The full-length cDNA clone of O/HN/CHA/93 was constructed by the following ligations. First, the Spe I$\mathrm{Xba}$ I fragment (Z12) derived from pMDZ12 was ligated into pSK-Z3M plasmid which was digested with the same enzymes. The resulting plasmid was named pSK-Z123. Then, the $B g l$ II-Not I fragment (Z4) derived from pSKZ4 was cloned into Bgl II- and Not I-digested pSK-Z123 plasmid, leading to the construct pOFS, which containing the full-length genome of FMDV O/HN/CHA/93 vaccine strain. The full-length clone was fully sequenced to ensure that additional mutations had not been introduced during cloning. Figure 2 illustrates the strategy for the construction of the full-length cDNA clone.

\section{Construction of genetically modified FMDV full-length cDNA clone}

For construction of genetically modified FMDV fulllength cDNA clone, overlap PCR fusion were used to introduce six amino acids substitutions at G-H loop of VP1 $(134 \mathrm{C} \rightarrow \mathrm{S}, 137 \mathrm{~S} \rightarrow \mathrm{G}, 139 \mathrm{~A} \rightarrow \mathrm{T}, 140 \mathrm{R} \rightarrow \mathrm{S}$, $142 \mathrm{~V} \rightarrow \mathrm{T}, 142 \mathrm{~S} \rightarrow \mathrm{N}$ ). In brief, individual parts were amplified with ZP1F/ZP3R and ZP2F/ZP4R primer pairs, respectively, and then these two fragments were fused by a second round of PCR with primers ZP1F and ZP4R. Consequently, the desired mutations were in the center of ZP2R and ZP3F primers. The resulting amplicon was then digested with BssH II/Xma I and cloned into pSKZ3M plasmid, which had been digested with the same enzymes, leading to the positive clone pSK-Z3MT. The correct nucleotides were confirmed by complete DNA sequencing. Then, the plasmid pSK-Z3MT was used as the backbone for the followings site-directed mutagenesis to produce amino acid substitutions $(1 \mathrm{C} 58 \mathrm{E} \rightarrow \mathrm{D}$, 1D $43 \mathrm{~T} \rightarrow \mathrm{K}$, and $48 \mathrm{I} \rightarrow \mathrm{V}$ ) with HN2729F/HN2729R, HN3341F/HN3341R, and HN3356F/HN3356R primer pairs using Quick-Change ${ }^{\circledR}$ Multi Site-Directed Mutagenesis Kit, respectively. After three rounds of site-directed mutagenesis, the resulting clone named pSK-Z3MT $\Delta$, was sequenced to confirm that the expected modifications had been introduced during amplification. Finally, the plasmid pSK-Z3MT $\Delta$ was digested with Spe I/Bgl II and cloned into the corresponding region of pOFS plasmid to produce genetically modified FMDV fulllength cDNA clone pOFSM. The final modified construct was confirmed by complete DNA sequencing. Table 3 lists the primers used for site-directed mutagenesis and overlap PCR fusion. 


\section{Recovery of viruses}

The full-length cDNA clone and its derivative were linearized by digestion with Not I and purified using QIAquick PCR Purification Kit (Qiagen). Confluent
BSR-T7/5 cells $\left(4-6 \times 10^{6}\right.$ in a six-well plate) were separately transfected with mixtures of $2.5 \mu \mathrm{g}$ linearized plasmid DNAs and $15 \mu$ l Lipofectamine ${ }^{\mathrm{TM}} 2000$ (Invitrogen) in a total volume of $1 \mathrm{ml}$ OptiMEM. After $5 \mathrm{~h}$

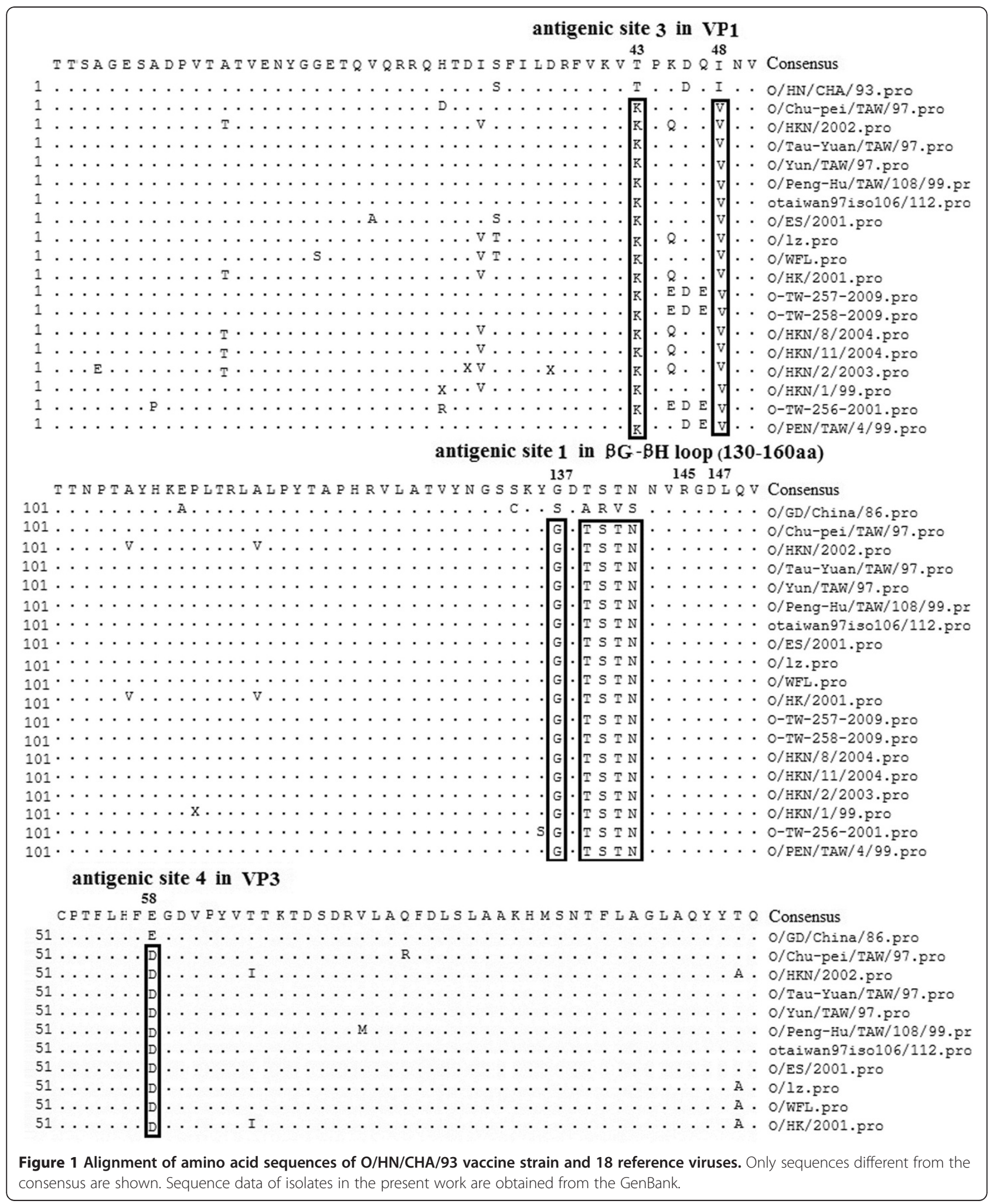


Table 2 Nucleotide sequence of PCR primers used for the construction of FMDV O/HN/CHA/93 full-length CDNA clone

\begin{tabular}{|c|c|c|}
\hline Name & Nucleotide Sequence $\left(5^{\prime} \rightarrow 3^{\prime}\right)$ & $\begin{array}{l}\text { Nucleotide } \\
\text { Position (nt) }\end{array}$ \\
\hline \multirow[t]{2}{*}{ Z1 } & AGACTAGTtaatacgactcactata ${ }_{T 7 p r o m o t e r} G G G T T G$ & $1-20$ \\
\hline & AAAGGGGGCGCTAGGGT & \\
\hline $\mathrm{Z1} 1^{\prime}$ & GAGGAGGGGGGGGGGGGGGGTGAAAG & $363-388$ \\
\hline Z2 & СТTСАСССССССССССССССТССТC & $363-388$ \\
\hline Z2' & GAAGCAACAGTGCTGCTACT & $721-740$ \\
\hline Z3 & CGCGCCGTCGCTTGAGGAAG & $560-579$ \\
\hline$Z^{\prime}$ & GGGTCGGAGCTCCTCCTTGATAGA & $5433-5456$ \\
\hline Z4 & AGCCACCTCTTCAGAACGTCTACC & $5242-5265$ \\
\hline Z4' & ACGCGGCCGCTIIIIIIIIIIIIIIIITाT & $3^{\prime}$ end \\
\hline Ztu1 & GGAGAGCGAGTCAGATA ATCTTCTTCACTACA & $4221-4251$ \\
\hline Ztu1' & TGTAGTGAAGAAGAIATCTGACTCGCTCTCC & $4221-4251$ \\
\hline Ztu2 & 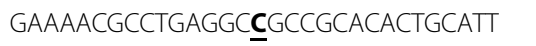 & 2967-2997 \\
\hline Ztu2' & AATGCAGTGTGCGGCGGCCTCAGGCGTTTC & 2967-2997 \\
\hline
\end{tabular}

Restriction enzyme sites introduced during clone construction are boxed. Mutated nucleotides are underlined and in bold.

at $37^{\circ} \mathrm{C}, 1 \mathrm{ml}$ of GMEM supplemented with $4 \%$ tryptose phosphate broth and 10\% FBS was added, and incubation continued for 2 to 3 days at $37^{\circ} \mathrm{C}$. The supernatants were collected when CPE appeared. Each supernatant was then serially passaged for further experiments. The total RNA was extracted from passage 4 supernatant of each rescued virus and analyzed by RT-PCR followed by sequencing to verify that the rescued viruses were derived from the cDNA plasmids. The rescued viruses generated from the full-length plasmids pOFS and pOFSM were then designted as r-HN and $\mathrm{rM}-\mathrm{HN}$, respectively.

\section{Replication kinetics of rescued FMDV}

To determine the replication kinetics of wild virus and rescued viruses in more detail, one-step growth was analyzed. BHK-21 cell monolayers were infected with wild $\mathrm{O} / \mathrm{HN} / \mathrm{CHA} / 93$ virus as well as two rescued viruses at a MOI of $0.1 \mathrm{TCID}_{50}$ per cell. The cells were washed at $1 \mathrm{~h}$ postinfection, and then incubated at $37^{\circ} \mathrm{C}$ for 4,8 , 12 and $16 \mathrm{~h}$. After incubation, infected cell cultures were harvested at $4 \mathrm{~h}$ intervals and the titer of infectious progeny was determined with $\mathrm{TCID}_{50}$ per milliliter using Reed-Muench formula.

\section{Stability of the genetically modified virus}

Progeny viruses obtained from the full-length plasmids were serially passaged 10 times in BHK-21 cells. Viral RNA was extracted from virus stocks collected at passages 5 and 10. P1 coding region was amplified by RTPCR and analyze to evaluate the genetic stability of the recombinant viruses.

\section{Serological cross-reactivity}

Swine serums against O/HN/CHA/93 and rM-HN viruses were prepared by 28 days post vaccination using BEI-inactivated $146 \mathrm{~S}$ particles. O/Tibet/CHA/99, O/ $\mathrm{TAW} / \mathrm{TL} / 97$ and $\mathrm{O} / \mathrm{JX} / \mathrm{CHA} / 2010$ isolates were assessed for their serological relationship (r-value) to the $\mathrm{O} / \mathrm{HN} /$ $\mathrm{CHA} / 93$ and rM-HN in a two-dimensional neutralisation test as described elsewhere [31].

\section{Swine immunization and challenge}

A total of 110 six-week-old pigs were randomly allocated to nine groups. Six groups (groups 1-6) consisted of 16 pigs each; whereas three groups of 2 pigs each (groups 7-9) were used as control groups. All animals were seronegative for FMDV 3ABC non-structural protein (NSP) antibodies prior to experimental vaccination. Two water-

Table 3 Nucleotide sequence of PCR primers used for the construction of genetically modified clone

\begin{tabular}{|c|c|c|}
\hline Name & Nucleotide Sequence $\left(5^{\prime} \rightarrow 3^{\prime}\right)$ & Nucleotide Position (nt) \\
\hline HN2729F & TCCTACACTTCGACGGTGACGTACCGTAC & $2729-2752(E \rightarrow D)$ \\
\hline HN2729R & GTACGGTACGTCACCGTCGAAGTGTAGGA & $2729-2752(E \rightarrow D)$ \\
\hline HN3341F & GATTTGTGAAAGTCA $\underline{\text { AAACCAAAAGACCAAAT }}$ & $3341-3371(\mathrm{~T} \rightarrow \mathrm{K})$ \\
\hline HN3341R & ATTTGGTCTITGGTIITGACTTCACAAATC & $3341-3371(T \rightarrow K)$ \\
\hline HN3356F & CACCAAAAGACCAAGTCAATGTGCTGGACC & $3356-3385(I \rightarrow V)$ \\
\hline HN3356R & GGTCCAGCACATTGACITTGGTCTITTGGTG & $3356-3385(I \rightarrow V)$ \\
\hline ZP1F & CAACCTACACTTCATGTTCACAGG & 2883-2906 \\
\hline \multirow[t]{2}{*}{ ZP2R } & AGACGGTCGCTACAACGGAAGTAGGTAAG & $3610-3659(C \rightarrow \mathrm{S}, \mathrm{S} \rightarrow \mathrm{G}, \mathrm{A} \rightarrow \mathrm{T}$, \\
\hline & TACGGTGACACCAGGCACGAAC & $\mathrm{R} \rightarrow \mathrm{S}, \mathrm{V} \rightarrow \mathrm{T}, \mathrm{S} \rightarrow \mathrm{N})$ \\
\hline \multirow[t]{2}{*}{ ZP3F } & GITCGTGCTGGIIGTCACCGTACTTACI A & $3610-3659(C \rightarrow \mathrm{S}, \mathrm{S} \rightarrow \mathrm{G}, \mathrm{A} \rightarrow \mathrm{T}$, \\
\hline & CTTCCGTTGTAGCGACCGTCT & $\mathrm{R} \rightarrow \mathrm{S}, \mathrm{V} \rightarrow \mathrm{T}, \mathrm{S} \rightarrow \mathrm{N})$ \\
\hline ZP4R & TGCTTGTGTCTAGCGTCACTCG & $3815-3836$ \\
\hline
\end{tabular}

Mutated nucleotides are underlined and in bold and the codon of the mutation effects are indicated in bold. Amino acid changes are shown in brackets. 
in-oil-in-water (WOW) vaccines were prepared from $\mathrm{O} /$ $\mathrm{HN} / \mathrm{CHA} / 93$ and rM-HN to contain $2 \mu \mathrm{g}$ of BEIinactivated, sucrose density gradient purified $146 \mathrm{~S}$ FMDV antigen per $2 \mathrm{ml}$ dose. The inactivated FMDV antigen was emulsified with Montanide ISA 206 (Seppic, France) oil. Groups 1, 3, and 5 were vaccinated with $2 \mathrm{ml}$ vaccine containing inactivated $\mathrm{O} / \mathrm{HN} / \mathrm{CHA} / 93$ virus as antigen. Subsequently, groups 2,4 , and 6 were vaccinated with $2 \mathrm{ml}$ vaccine containing inactivated $\mathrm{rM}-\mathrm{HN}$ virus as antigen, whereas groups 7,8 , and 9 were inoculated with minimal essential medium as non-vaccinated. At 28 days post vaccination (dpv), all pigs were challenged intramuscularly with $10^{5}$ TCID50/2 $\mathrm{ml}$ of different FMDV at the earroot-neck area. Briefly, groups 1, 2, and 7 were challenged with $\mathrm{O} / \mathrm{Tibet} / \mathrm{CHA} / 99$ virus. Groups 3,4 , and 8 were challenged with O/TAW/TL/97 virus. Groups 5, 6, and 9 were challenged with $\mathrm{O} / \mathrm{JX} / \mathrm{CHA} / 2010$ virus. Serum samples were collected from all animals on 0 and $28 \mathrm{dpv}$ for virus neutralization titer analysis as described previously [32]. The neutralizing antibody titers were calculated as the $\log _{10}$ of the reciprocal antibody dilution required for $50 \%$ neutralization of $100 \mathrm{TCID}_{50}$ viruses. The animals were then observed for the appearance of clinical signs of FMD daily for 14 days post challenge. Lesions were defined as described previously [33]. Briefly, localized lesions: vesicles observed on snout, lips, or one foot during the postchallenge period; generalized lesions: vesicles observed on snout, lips, and one or more feet during the postchallenge period. Two-week post-challenge, all animals were rebled, and sera were tested for the presence of antibodies to the FMDV non-structural proteins (NSP) 3ABC, using the commercially available 3ABC-I-ELISA kit. Samples were considered positive if the cutoff value $\geq 0.2$. All animal studies were approved by the Review Board of Lanzhou Veterinary Research Institute, Chinese Academy of Agricultural Sciences (Permission number: SYXKGAN-2004-0005). All animals used in the present study were humanely bred to bleed during the experiment and euthanasia was carried out at the end of the experiment.

\section{Results}

Amino acid variation of FMDV isolates of $\mathrm{CHY}$ topotype

Deduced amino acid sequence alignments were performed with the data for each isolates of CHY topotype using SeqMan II. The results indicated that numerous amino acid replacements occurred in the P1 or VP1 capsid region of the isolates of CHY topotype. These viruses shared consensus amino acids substitutions at antigenic site $1(134 \mathrm{C} \rightarrow \mathrm{S}, 137 \mathrm{~S} \rightarrow \mathrm{G}, 139 \mathrm{~A} \rightarrow \mathrm{T}, 140 \mathrm{R} \rightarrow \mathrm{S}$, $141 \mathrm{~V} \rightarrow \mathrm{T}, 142 \mathrm{~S} \rightarrow \mathrm{N}), 3(43 \mathrm{~T} \rightarrow \mathrm{K}, 48 \mathrm{I} \rightarrow \mathrm{V})$, and 4 $(58 \mathrm{E} \rightarrow \mathrm{D})$, compared with the $\mathrm{O} / \mathrm{HN} / \mathrm{CHA} / 93$ vaccine strain. The variations in the antigenic sites may render the available vaccine ineffective. The differences of amino acid sequences of FMDV isolates were showed in Figure 1.

\section{Generation of viruses}

FMDV full-length cDNA clone, pOFS, was constructed in the M-pSK vector from the O/HN/CHA/93 vaccine strain. A genetically modified full-length clone, pOFSM, was assembled using overlap PCR fusion and SiteDirected Mutagenesis, based on the established infectious clone. The modified construct had nine amino acid differences (VP1 $43 \mathrm{~T} \rightarrow \mathrm{K}, 48 \mathrm{I} \rightarrow \mathrm{V}, 134 \mathrm{C} \rightarrow \mathrm{S}$, $137 \mathrm{~S} \rightarrow \mathrm{G}, 139 \mathrm{~A} \rightarrow \mathrm{T}, 140 \mathrm{R} \rightarrow \mathrm{S}, 142 \mathrm{~V} \rightarrow \mathrm{T}, 142 \mathrm{~S} \rightarrow \mathrm{N}$, VP3 $58 \mathrm{E} \rightarrow \mathrm{D}$ ) by sequence analysis, compared with the pOFS clone. Linearized pOFS and POFSM plasmids were transfected into BSR-T7/5 cells to verify whether cDNA clones were infectious. In day 2 post-transfection, CPE appeared in both clones, indicating that the two full-length clones were infectious. Furthermore, some amino acid substitutions in the vaccine strain genome did not have an effect on the ability of viral replication in vitro.

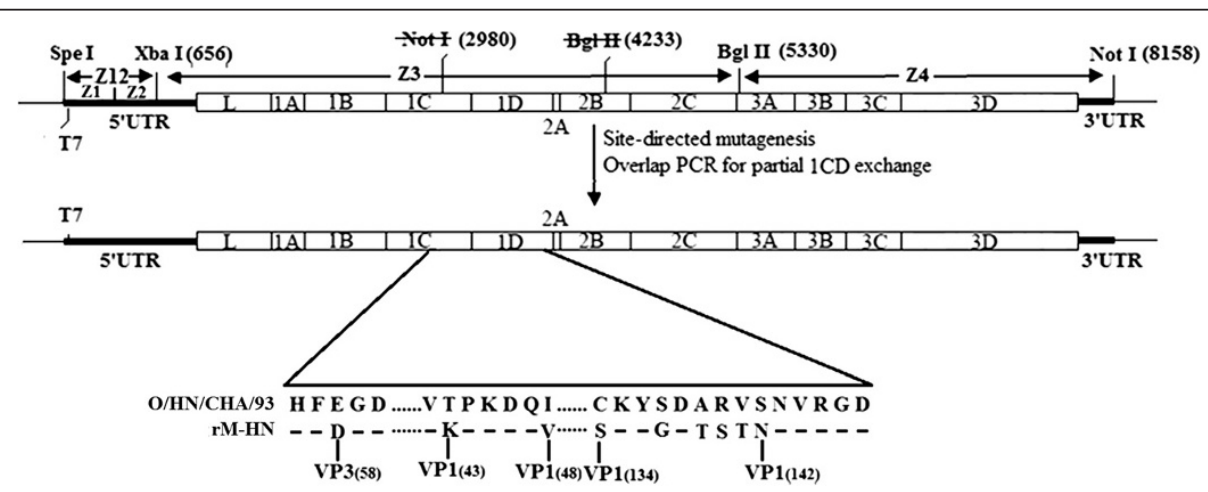

Figure 2 Strategy used to construct FMDV O/HN/CHA/93 full-length cDNA clone and genetically modified clone. The location of the restriction enzyme cleavage sites used to assemble the subcloned PCR fragments (Z1, Z2, Z3 and Z4) are shown (numbered relative to nucleotide position in the virus genome). Thick lines and an open box represent the untranslated regions and the open-reading frame for the viral polyprotein, respectively. The thin line represents the vector sequence. FMDV cDNA is under the control of the T7 promoter. 
RT-PCR was performed to amplify targeted fragments including genetic tags or targeted amino acid substitutions from viral RNAs of passage 4 to verify that the two rescued viruses were of recombinant origin. The result of sequence analysis confirmed that the recovered viruses were indeed derived from the respective recombinant plasmids.

\section{Replication kinetics of rescued FMDV}

Single-step growth curves of the rescued viruses and the wild virus were performed on BHK-21 cells. The results showed that the rescued viruses had the similar replication properties to the parental virus on BHK-21 cells (Figure 3). These results suggest that the substitutions of amino acid in capsid protein do not affect the ability of viral replication in vitro.

\section{Stability of the genetically modified FMDV}

The recombinant $\mathrm{r}-\mathrm{HN}$ and $\mathrm{rM}-\mathrm{HN}$ viruses were serially passaged 10 times in BHK-21 cells. Consequently, the amino acid sequence of $\mathrm{P} 1$ coding regions of the recombinant viruses recovered from passages 5 and 10 were analyzed. The results revealed that the rescued viruses remained genetically stable during 10 serial passages in vitro.

\section{Serological cross-reactivity}

The relative homology value $(\mathrm{r} 1)$ between field isolate (O/Tibet/CHA/99, O/TAW/TL/97, and O/JX/CHA/ 2010) and reference strains $(\mathrm{O} / \mathrm{HN} / \mathrm{CHA} / 93$ and rM$\mathrm{HN}$ ) were determined using two dimensional micro neutralization tests (Table 4) as previously described [34]. The results showed that the O/HN/CHA/93

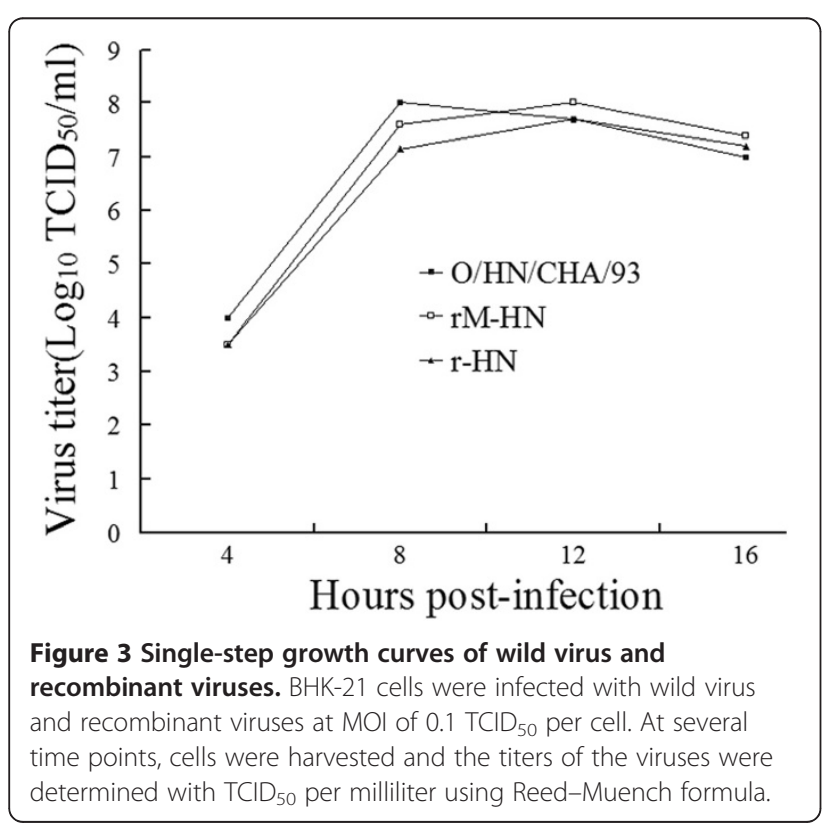

Table 4 The " $r$ " values obtained between field isolates and reference strains

\begin{tabular}{lll}
\hline Virus & O/HN/CHA/93 & rM-HN \\
\hline O/Tibet/CHA/99 & 0.57 & 0.60 \\
O/TAW/TL/97 & 0.28 & 0.45 \\
O/JX/CHA/2010 & 0.59 & 0.54 \\
\hline
\end{tabular}

reference strains have close antigenic relationship with $\mathrm{O} /$ Tibet/CHA/99 and O/JX/CHA/2010 isolates, but the $\mathrm{O} / \mathrm{TAW} / \mathrm{TL} / 97$ isolate is antigenically related to the $\mathrm{O} / \mathrm{HN} / \mathrm{CHA} / 93$ vaccine strain, which indicates that a more potent vaccine strain needs to be developed against the variants of the $\mathrm{CHY}$ topotype. However, the rM-HN virus has close antigenic relationship with isolates of three topotypes compared with the wild $\mathrm{O} / \mathrm{HN} /$ $\mathrm{CHA} / 93$ virus. Therefore, this virus would be used as a vaccine candidate.

\section{Swine protection experiments}

To test the protective efficacy of the inactivated oilemulsified vaccines that were prepared from wild $\mathrm{O} / \mathrm{HN} /$ $\mathrm{CHA} / 93$ strain and the genetically modified virus rM$\mathrm{HN}$ against the viruses of three topotypes, the present study designed a swine vaccination and challenge studies. All pigs immunized with vaccine prepared from rM-HN were fully protected from clinical disease and viral infection after challenge with O/Tibet/CHA/99, O/TAW/TL/ 97, and O/JX/CHA/2010 viruses. No clinical signs of FMD were detected in these vaccinated pigs. The pigs vaccinated with $\mathrm{O} / \mathrm{HN} / \mathrm{CHA} / 93$ vaccine were completely protected against O/Tibet/CHA/99 and O/JX/CHA/2010 virus infection. However, 4 of the 16 pigs developed localized lesions after O/TAW/TL/97 virus infection, although these animals had a delayed appearance of vesicles (4-5 dpc) compared with the control swine. All control animals in groups 7, 8, and 9 developed generalized FMD and clinical signs of FMD appeared 2 to 3 days after the infection of these viruses. All immunized pigs developed a higher neutralizing antibody against these viruses, except for the immunized pigs that produced clinical signs of FMD. The present study indicated that vaccine prepared from genetically modified FMDV by reverse genetics significantly improved protective efficacy to the variant of the CHY topotype, compared with the O/HN/CHA/93 strain. Tables 5,6 , and 7 present the results of swine protection experiments. Two weeks post-challenge, animals were rebled and sera were tested for the presence of antibodies to the nonstructural protein $3 \mathrm{ABC}$. As expected, antibodies against NSP 3ABC could be detected in unvaccinated controls and in the four immunized pigs that produced clinical signs of FMD after 14 days postchallenge. Whereas all of the other vaccinated pigs remained NSP seronegative (Tables 5, 6, and 7). 


\section{Discussion}

FMD remains one of the most economically important diseases of farm animals and is widespread across the world, especially in Africa, Asia and South America. Type O FMD is prevalent in China (including Chinese Taipei, Chinese Hong Kong) and its surrounding countries [10-13]. Among the epidemic topotypes in these regions, the viruses in $\mathrm{CHY}$ topotype are highly adapted to pigs [15], which represents the biggest threat on the Chinese hog industry and the economy. For instance, in 1997, a devastating and unusual outbreak of FMD occurred in Taiwan. The outbreak, which was caused by a $\mathrm{CHY}$ topotype virus, rapidly developed into massive epizootic, resulting in the slaughter of more than 4 million pigs and financial losses of over 6 billion U.S. dollars $[35,36]$. China is the biggest pork producer and consumer in the world and the pig industry has become the most important sector in Chinese animal husbandry [37]. Therefore, control of FMD in swine has become high priority. Vaccination as a control tool has been gaining favor as a potentially more effective approach for controlling the virus, reducing the economic loss to animal husbandry, and contributing to improved food security in China. However, currently available FMD vaccines in China often do not provide complete protection against some variants arising in the $\mathrm{CHY}$ topotype.

Extensive studies has showed that the $\mathrm{G}-\mathrm{H}$ loop of FMDV is the major immunodominant site [38,39], and it can induce a strong antibody response against the virus, which is known to play a major role in protection induced by the current FMDV vaccines [9]. Experimental peptide or recombinant vaccines $[40,41]$ have been based mainly on this major antigenic site of FMDV. In addition, FMDV antigenic variation also occurs within other antigenic sites, which are implicated in the full complete immunologic response [9,42]. Based on these theories, the present study compared amino acid sequences of the capsid region of $\mathrm{O} / \mathrm{HN} / \mathrm{CHA} / 93$ vaccine strain and 18 reference isolates of $\mathrm{CHY}$ topotype. The results revealed that consensus amino acid substitutions occurred at VP1 $(43 \mathrm{~T} \rightarrow \mathrm{K}, 48 \mathrm{I} \rightarrow \mathrm{V} 134 \mathrm{C} \rightarrow \mathrm{S}, 137 \mathrm{~S} \rightarrow \mathrm{G}$, $139 \mathrm{~A} \rightarrow \mathrm{T}, 140 \mathrm{R} \rightarrow \mathrm{S}, 141 \mathrm{~V} \rightarrow \mathrm{T}, 142 \mathrm{~S} \rightarrow \mathrm{N}$ ) and VP3 $(58 \mathrm{E} \rightarrow \mathrm{D})$, which are involved in antigenic site 1,3 , and 4 . Among these substitutions, six were located at the $\mathrm{G}-\mathrm{H}$ loop of VP1 and three were located at a position

Table 5 Responses of pigs to vaccination with $\mathrm{O} / \mathrm{HN} / \mathrm{CHA} / 93$ and $\mathrm{rM}-\mathrm{HN}$ vaccines and O/Tibet/CHA/99 challenge

\begin{tabular}{|c|c|c|c|c|c|c|c|c|c|}
\hline \multirow[t]{2}{*}{ Vaccine $^{a}$} & \multirow[t]{2}{*}{ Pig no. } & \multirow[t]{2}{*}{$\begin{array}{l}\text { VNT titer versus } \\
\text { O/Tibet/CHA/99 }\end{array}$} & \multicolumn{2}{|c|}{$\begin{array}{c}\text { Response to challenge } \\
\text { with } \mathrm{O} / \mathrm{Tibet} / \mathrm{CHA} / 99\end{array}$} & \multirow[t]{2}{*}{ Vaccine $^{a}$} & \multirow[t]{2}{*}{ Pig no. } & \multirow[t]{2}{*}{$\begin{array}{l}\text { VNT titer versus } \\
\text { O/Tibet/CHA/99 }\end{array}$} & \multicolumn{2}{|c|}{$\begin{array}{c}\text { Response to challenge } \\
\text { with O/Tibet/CHA/99 }\end{array}$} \\
\hline & & & Lesions $^{c}$ & $3 A B C^{d}$ & & & & Lesions $^{c}$ & $3 A B C^{d}$ \\
\hline \multirow[t]{16}{*}{ O/HN/CHA/93 } & 101 & 1.6 & - & - & \multirow[t]{16}{*}{$\mathrm{rM}-\mathrm{HN}$} & 601 & 2.1 & - & - \\
\hline & 102 & 1.7 & - & - & & 202 & 1.6 & - & - \\
\hline & 103 & 2.0 & - & - & & 203 & 1.6 & - & - \\
\hline & 104 & 1.7 & - & - & & 204 & 2.0 & - & - \\
\hline & 105 & 1.5 & - & - & & 205 & 1.8 & - & - \\
\hline & 106 & 2.1 & - & - & & 206 & 2.1 & - & - \\
\hline & 107 & 1.8 & - & - & & 207 & 1.7 & - & - \\
\hline & 108 & 2.0 & - & - & & 208 & 1.9 & - & - \\
\hline & 109 & 1.5 & - & - & & 209 & 1.8 & - & - \\
\hline & 110 & 1.9 & - & - & & 210 & 2.0 & - & - \\
\hline & 111 & 2.1 & - & - & & 211 & 1.8 & - & + \\
\hline & 112 & 1.9 & - & - & & 212 & 2.0 & - & - \\
\hline & 113 & 1.8 & - & - & & 213 & 1.6 & - & - \\
\hline & 114 & 1.6 & - & - & & 214 & 2.1 & - & - \\
\hline & 115 & 2.1 & - & - & & 215 & 1.7 & - & - \\
\hline & 116 & 1.7 & - & - & & 216 & 2.0 & - & - \\
\hline \multirow[t]{2}{*}{ Control } & 117 & $<1.0$ & ++ & + & \multirow[t]{2}{*}{ Control } & 217 & $<1.0$ & ++ & + \\
\hline & 118 & $<1.0$ & ++ & + & & 218 & $<1.0$ & ++ & + \\
\hline
\end{tabular}

\footnotetext{
a BEl-inactivated virus.

${ }^{\mathrm{b}}$ Day 28 virus neutralization titer (expressed as the $\log _{10}$ of the reciprocal antibody dilution required for $50 \%$ neutralization of 100 TCID 50 virus) values represent the means from two repeat tests.

'Scoring of clinical signs: -, no visible lesions, + , localized gross lesions; ++ , generalized lesions.

${ }^{d}$ Presence of antibodies to the nonstructural protein $3 A B C$ in sera collected 14 days post-challenge, determined by the commercially available $3 A B C-I-E L I S A$ kit. Samples were considered positive if the cutoff value $\geq 0.2$.
} 
Table 6 Responses of pigs to vaccination with O/HN/CHA/93 and rM-HN vaccines and O/TAW/TL/97 challenge

\begin{tabular}{|c|c|c|c|c|c|c|c|c|c|}
\hline \multirow[t]{2}{*}{ Vaccine $^{a}$} & \multirow[t]{2}{*}{ Pig no. } & \multirow[t]{2}{*}{$\begin{array}{l}\text { VNT titer versus } \\
\text { O/TAW/TL/97 }\end{array}$} & \multicolumn{2}{|c|}{$\begin{array}{c}\text { Response to challenge } \\
\text { with } 0 / T A W / T L / 97\end{array}$} & \multirow[t]{2}{*}{ Vaccine $^{a}$} & \multirow[t]{2}{*}{ Pig no. } & \multirow[t]{2}{*}{$\begin{array}{l}\text { VNT titer versus } \\
\text { O/TAW/TL/97 }\end{array}$} & \multicolumn{2}{|c|}{$\begin{array}{l}\text { Response to challenge } \\
\text { with O/TAW/TL/97 }\end{array}$} \\
\hline & & & Lesions $^{c}$ & $3 A B C^{d}$ & & & & Lesions $^{c}$ & $3 A B C^{d}$ \\
\hline \multirow[t]{16}{*}{$\mathrm{O} / \mathrm{HN} / \mathrm{CHA} / 93$} & 301 & 1.8 & - & - & $\mathrm{rM}-\mathrm{HN}$ & 401 & 2.1 & - & - \\
\hline & 302 & 1.5 & - & - & & 402 & 1.6 & - & - \\
\hline & 303 & 1.7 & - & + & & 403 & 1.6 & - & - \\
\hline & 304 & 1.5 & - & - & & 404 & 1.9 & - & - \\
\hline & 305 & 1.6 & - & - & & 405 & 1.8 & - & - \\
\hline & 306 & 1.7 & - & - & & 406 & 2.1 & - & - \\
\hline & 307 & 0.7 & + & + & & 407 & 1.7 & - & - \\
\hline & 308 & 1.5 & - & - & & 408 & 1.6 & - & - \\
\hline & 309 & 1.6 & - & - & & 409 & 1.8 & - & - \\
\hline & 310 & 0.8 & + & + & & 410 & 2 & - & - \\
\hline & 311 & 1.8 & - & - & & 411 & 1.8 & - & - \\
\hline & 312 & 1.0 & + & + & & 412 & 1.7 & - & - \\
\hline & 313 & 1.5 & - & - & & 413 & 1.6 & - & - \\
\hline & 314 & 1.6 & - & - & & 414 & 2.1 & - & - \\
\hline & 315 & 1.7 & - & - & & 415 & 1.7 & - & - \\
\hline & 316 & 0.8 & + & + & & 416 & 1.6 & - & - \\
\hline \multirow[t]{2}{*}{ Control } & 317 & $<1.0$ & ++ & + & Control & 417 & $<1.0$ & ++ & + \\
\hline & 318 & $<1.0$ & ++ & + & & 418 & $<1.0$ & ++ & + \\
\hline
\end{tabular}

$a, b, c, d$ described as above.

Table 7 Responses of pigs to vaccination with O/HN/CHA/93 and rM-HN vaccines and O/JX/CHA/2010 challenge

\begin{tabular}{|c|c|c|c|c|c|c|c|c|c|}
\hline \multirow[t]{2}{*}{ Vaccine $^{a}$} & \multirow[t]{2}{*}{ Pig no. } & \multirow[t]{2}{*}{$\begin{array}{l}\text { VNT titer versus } \\
\mathrm{O} / \mathrm{JX} / \mathrm{CHA} / 2010^{\mathrm{b}}\end{array}$} & \multicolumn{2}{|c|}{$\begin{array}{c}\text { Response to challenge } \\
\text { with } \mathrm{O} / \mathrm{JX} / \mathrm{CHA} / 2010\end{array}$} & \multirow[t]{2}{*}{ Vaccine $^{a}$} & \multirow[t]{2}{*}{ Pig no. } & \multirow[t]{2}{*}{$\begin{array}{l}\text { VNT titer versus } \\
\mathrm{O} / \mathrm{JX} / \mathrm{CHA} / 2010^{\mathrm{b}}\end{array}$} & \multicolumn{2}{|c|}{$\begin{array}{c}\text { Response to challenge } \\
\text { with } \mathrm{O} / \mathrm{JX} / \mathrm{CHA} / 2010\end{array}$} \\
\hline & & & Lesions $^{c}$ & $3 A B C^{d}$ & & & & Lesions $^{c}$ & $3 A B C^{d}$ \\
\hline \multirow[t]{16}{*}{$\mathrm{O} / \mathrm{HN} / \mathrm{CHA} / 93$} & 501 & 1.6 & - & - & $\mathrm{rM}-\mathrm{HN}$ & 601 & 1.9 & - & - \\
\hline & 502 & 2.3 & - & - & & 602 & 2.1 & - & - \\
\hline & 503 & 1.7 & - & - & & 603 & 1.6 & - & - \\
\hline & 504 & 2.0 & - & - & & 604 & 1.7 & - & + \\
\hline & 505 & 1.9 & - & - & & 605 & 2.0 & - & - \\
\hline & 506 & 2.0 & - & - & & 606 & 1.8 & - & - \\
\hline & 507 & 2.2 & - & - & & 607 & 2.0 & - & - \\
\hline & 508 & 1.7 & - & + & & 608 & 2.1 & - & - \\
\hline & 509 & 2.1 & - & - & & 609 & 1.7 & - & - \\
\hline & 510 & 1.8 & - & - & & 610 & 2.0 & - & - \\
\hline & 511 & 2.1 & - & - & & 611 & 1.7 & - & - \\
\hline & 512 & 1.9 & - & - & & 612 & 2.0 & - & - \\
\hline & 513 & 1.6 & - & - & & 613 & 1.9 & - & - \\
\hline & 514 & 1.8 & - & - & & 614 & 1.8 & - & - \\
\hline & 515 & 1.6 & - & - & & 615 & 1.7 & - & - \\
\hline & 516 & 2.2 & - & - & & 616 & 1.7 & - & - \\
\hline \multirow[t]{2}{*}{ Control } & 517 & $<1.0$ & ++ & + & Control & 617 & $<1.0$ & ++ & + \\
\hline & 518 & $<1.0$ & ++ & + & & 618 & $<1.0$ & ++ & + \\
\hline
\end{tabular}


critical for antigenic sites 3 and 4. Any alteration of critical residues would confer antigenic specificity to the FMD viral variants [43-45]. Therefore, we presumed that the antigenic differences between the variants of $\mathrm{CHY}$ topotype and the current vaccine strain might account for incomplete protection.

Previous successes in the generation of engineered avirulent, chimeric, and thermostable FMDV vaccine candidates $[33,46,47]$ have further provided insight for designing new vaccine candidate viruses with engineered modifications by reverse genetics. Therefore, the present study constructed a full-length infectious clone of $\mathrm{O} /$ HN/CHA/93 vaccine strain and created a genetically modified construct with amino acid substitutions (1 C $58 \mathrm{E} \rightarrow \mathrm{D}, 1 \mathrm{D} 43 \mathrm{~T} \rightarrow \mathrm{K}, 48 \mathrm{I} \rightarrow \mathrm{V}, 134 \mathrm{C} \rightarrow \mathrm{S}, 137 \mathrm{~S} \rightarrow \mathrm{G}$, $139 \mathrm{~A} \rightarrow \mathrm{T}, 140 \mathrm{R} \rightarrow \mathrm{S}, 141 \mathrm{~V} \rightarrow \mathrm{T}, 142 \mathrm{~S} \rightarrow \mathrm{N}$ ), based on vaccine strain framework using a similar strategy. As expected, a genetically modified virus was obtained from the modified full-length plasmid. Specifically, amino acid substitutions in the capsid protein did not affect the in vitro infectivity properties of the recombinant. Viability of the virus indicated that the genome of FMDV O/ HN/CHA/93 can tolerate these amino acid replacements at three antigenic sites. This finding was not surprising, because previous studies have demonstrated that FMDV can accommodate replacements of G-H loop, capsid coding region as well as other gene region of inter-genotypic and intra-genotypic [16,42,48-50]. The recombinant viruses were genetically stable after 10 serial passages in BHK-21 cells.

As a FMD vaccine candidate, the virus should necessarily grow to high yield in tissue culture for sufficient antigenic mass to be produced [51]. Therefore, the replicative properties of the recombinant viruses were assessed by single-step growth curves. The results indicated that the rescued viruses had similar growth properties to the wild $\mathrm{O} / \mathrm{HN} / \mathrm{CHA} / 93$ virus. In addition, an ideal vaccine candidate would induce cross protection against viruses from different antigenic groups within the subtype. Analysis of antigenic relationships between the field isolate of the three topotypes and the reference strains $(\mathrm{O} / \mathrm{HN} / \mathrm{CHA} / 93$ and $\mathrm{rM}-\mathrm{HN})$ showed that the $\mathrm{O} / \mathrm{HN} / \mathrm{CHA} / 93$ reference strains demonstrated close antigenic relationship with $\mathrm{O} /$ Tibet/CHA/99 and O/JX/ CHA/2010 isolates. However, the O/TAW/TL/97 isolate is antigenically related to the vaccine strain. The rM-HN virus had close antigenic relationship with isolates of the three topotypes compared with the O/HN/CHA/93 strain. Thus, this recombinant virus would be used as vaccine candidate. Comparative efficacy of the inactivated vaccines prepared from the $\mathrm{rM}-\mathrm{HN}$ and $\mathrm{O} / \mathrm{HN} /$ CHA/93 viruses were tested in swine. The results demonstrated that pigs vaccinated with the $\mathrm{O} / \mathrm{HN} /$ CHA/93 vaccine were fully protected from O/Tibet/
CHA/99 and $\mathrm{O} / \mathrm{JX} / \mathrm{CHA} / 2010$ virus challenge, but only $75 \%$ of the immunized animals were against O/TAW/ TL/97 infection. However, all pigs vaccinated with the $\mathrm{rM}-\mathrm{HN}$ vaccine obtained complete protection against $\mathrm{O} /$ Tibet/CHA/99, O/TAW/TL/97, and O/JX/CHA/2010 virus challenge, which may be contribute to the more antigentic similarities of the genetically modified virus with the isolate of $\mathrm{CHY}$ topotype.

\section{Conclusions}

The present study constructed a full-length infectious cDNA clone of FMDV vaccine strain and created a genetically modified virus with some amino acid substitutions in capsid protein, based on vaccine framework. Some amino acid substitutions in the FMDV vaccine strain genome did not have an effect on the ability of viral replication in vitro. The recombinant viruses had similar growth properties with the wild $\mathrm{O} / \mathrm{HN} / \mathrm{CHA} / 93$ virus. The vaccine prepared from genetically modified FMDV significantly improved protective efficacy to the variants of the $\mathrm{CHY}$ topotype, compared with the wild $\mathrm{O} / \mathrm{HN} / \mathrm{CHA} / 93$ virus. Thus, the full-length cDNA clone of FMDV can be a useful tool to develop genetically engineered FMDV vaccine candidates to help control porcinophilic FMD epidemics in China. Furthermore, the present study provided further insights for designing genetically modified FMD vaccine candidate by reverse genetics, based on the sequence information of arising mutants during the new FMD outbreak.

\section{Competing interests}

The authors declare that they have no competing interests.

\section{Authors' contributions}

PHL conceived and designed the study. XWB constructed the FMDV full-length infectious CDNA clone and modified construct. PS and DL carried out the animal experiments. ZJ performed sequence alignment. YMC and YFF performed virus neutralization assay. HFB, YLC and BXX passaged the recombinant viruses. PS contributed reagents, materials, and analysis tools. ZXL supervised all aspects of the research. PHL analyzed the data and drafted the manuscript. All authors read and approved the final manuscript.

\section{Acknowledgments}

We thank Karl-Klaus Conzelmann (Max von Pettenkofer Institute and Gene Center, Germany) for generously supplying the cells used in the present study. The current research was supported by National "863" project, 2011AA10A211.

Received: 15 September 2011 Accepted: 24 April 2012 Published: 16 May 2012

\section{References}

1. Bachrach HL: Foot and mouth disease virus. Annu Rev Microbiol 1968, 22:201-244.

2. Garland AJM: Vital elements for the successful control of foot-and-mouth disease by vaccination. Vaccine 1999, 17:1760-1766.

3. Pereira HG: Subtyping foot-and-mouth disease virus. Dev Biol Stand 1977, 35:167-174

4. Mateu MG, Da Silva JL, Rocha E, De Brum DL, Alonso A, Enjuanes L, Domingo $\mathrm{E}$, Barahona $\mathrm{H}$ : Extensive antigenic heterogeneity of footand-mouth disease virus of serotype C. Virology 1988, 167:113-124. 
5. Belsham GJ: Translation and replication of FMDV RNA. Curr Top Microbiol Immunol 2005, 288:43-70.

6. Kitson JDA, McCahon D, Belsham GJ: Sequence analysis of monoclonal antibody resistant mutants of type $\mathrm{O}$ foot-and mouth disease virus: evidence for the involvement of the three surface exposed capsid proteins in four antigenic sites. Virology 1990, 179:26-34.

7. Crowther JR, Farias S, Carpenter WC, Samuel AR: Identification of a fifth neutralizable site on type $\mathrm{O}$ foot-and-mouth disease virus following characterization of single and quintuple monoclonal antibody escape mutants. J Gen Virol 1993, 74:1547-1553.

8. Borrego B, Camarero JA, Mateu MG, Domingo E: A highly divergent antigenic site of foot-and-mouth disease virus retains its immunodominance. Viral Immunol 1995, 8:11-18.

9. Mateu MG, Camarero JA, Giralt E, Andreu D, Domingo E: Direct evaluation of the immunodominance of a major antigenic site of foot-and-mouth disease virus in a natural host. Virology 1995, 206:298-306.

10. Li ZY, Liu JX: The current state of vaccines used in the field for foot and mouth disease virus in China. Vaccine 2011, 10:13-15.

11. Lin YL, Jong MH, Huang CC, Shieh HK, Chang PC: Genetic and antigenic characterization of foot-and-mouth disease viruses isolated in Taiwan between 1998 and 2009. Vet Microbiol 2010, 145:34-40.

12. Chen JD, Zhao MQ, Hui KH, Leung FC: Molecular Characterization of Foot-and-mouth Disease Virus in Hong Kong During 2001-2002. Virus genes 2006, 32:139-143.

13. Gleeson $\perp:$ A review of the status of foot-and-mouth disease in South-East Asia and approaches to control and eradication. Rev Sci Tech Off Int Epiz 2002, 21:465-475.

14. Knowles NJ, Samuel AR: Molecular epidemiology of foot-and-mouth disease virus. Virus Res 2003, 91:65-80.

15. Samuel AR, Knowles NJ: Foot-and-mouth disease type $O$ viruses exhibit genetically and geographically distinct evolutionary lineages (topotypes). J Gen Virol 2001, 82:609-621.

16. Van Rensburg HG, Henry TM, Mason PW: Studies of genetically defined chimeras of a European type A virus and a South African Territories type 2 virus reveal growth determinants for foot-and-mouth disease virus. J Gen Virol 2004, 85:61-68.

17. Wang Y, Liang YJ, Han J, Burkhart KM, Vaughn EM, Roof MB, Faaberg KS: Attenuation of porcine reproductive and respiratory syndrome virus strain MN184 using chimeric construction with vaccine sequence. Virology 2008, 371:418-429.

18. Gillespie J, Juhan NM, Dicristina J, Key KF, Ramamoorthy S, Meng XJ: A genetically engineered chimeric vaccine against porcine circovirus type 2 (PCV2) is genetically stable in vitro and in vivo. Vaccine 2008, 26:4231-4236.

19. Fowler VL, Knowles NJ, Paton DJ, Barnett PV: Marker vaccine potential of a foot-and-mouth disease virus with a partial VP1 G-H loop deletion. Vaccine 2010, 28:3428-3434.

20. Hu S, Ma H, Wu Y, Liu W, Wang X, Liu Y, Liu X: A vaccine candidate of attenuated genotype VII Newcastle disease virus generated by reverse genetics. Vaccine 2009, 27:904-910.

21. Song JM, Lee YJ, Jeong OM, Kang HM, Kim HR, Kwon JH, Kim JH, Seong BL, Kim YJ: Generation and evaluation of reassortant influenza vaccines made by reverse genetics for H9N2 avian influenza in Korea. Vet Microbiol 2008, 130:268-276.

22. Cao Y, Lu Z, Sun P, Fu Y, Tian F, Hao X, Bao H, Liu X, Liu Z: A pseudotype baculovirus expressing the capsid protein of foot-and-mouth disease virus and a T-Cell immunogen shows enhanced immunogenicity in mice. Virol J 2011, 8:77.

23. Feng $Q$, Chen $X$, Ma O, Liu Y, Ding M, Collins RA, Ko LS, Xing J, Lau LT, Yu AC, Chen J: Serotype and VP1 gene sequence of a foot-and-mouth disease virus from Hong Kong (2002). Biochem Biophys Res Commun 2003, 30:715-721.

24. Feng $Q$, Yu H, Liu Y, He C, Hu J, Sang H, Ding N, Ding M, Fung YW, Lau LT, Yu AC, Chen J: Genome comparison of a novel foot-and-mouth disease virus with other FMDV strains. Biochem Biophys Res Commun 2004, 323:254-263.

25. Zhao MQ, Suo QL, Chen JD, Chen LJ, Xu YF: Sequence analysis of the protein-coding regions of foot-and-mouth disease virus $\mathrm{O} / \mathrm{HK} / 2001$. Vet Microbiol 2008, 130:238-246.

26. Buchholz UJ, Finke S, Conzelmann KK: Generation of bovine respiratory syncytial virus (BRSV) from CDNA: BRSV NS2 is not essential for virus replication in tissue culture, and the human RSV leader region acts as a functional BRSV genome promoter. J Virol 1999, 73:251-259.

27. Rieder E, Bunch T, Brown F, Mason PW: Genetically engineered foot-andmouth disease viruses with poly $(\mathrm{C})$ tracts of two nucleotides are virulent in mice. J Virol 1993, 67:5139-5145.

28. Paton DJ, King DP, Knowles NJ, Hammond J: Recent spread of foot-andmouth disease in the Far East. Vet Rec 2010, 166:569-70.

29. Sambrook J, Fitsch EF, Maniatis T: Molecular Cloning: A Laboratory Manual. Cold Spring Harbor Press: Cold Spring Harbor; 1989.

30. Li P, Lu Z, Bao H, Li D, King DP, Sun P, Bai X, Cao W, Gubbins S, Chen Y, Xie B, Guo J, Yin H, Liu Z: In-vitro and in-vivo phenotype of type Asia 1 footand-mouth disease viruses utilizing two non-RGD receptor recognition sites. BMC Microbiol 2011, 11:154

31. Rweyemamu MM, Hingley PJ: Foot-and-mouth disease virus strain differentiation: analysis of the serological data. J Biol Stand 1984, 12:191-194.

32. Baxt BD, Morgan O, Robertson BH, Timpone CA: Epitopes on foot-andmouth disease virus outer capsid protein VP1, involved in neutralization and cell attachment. J Virol 1984, 51:298-305.

33. Rieder E, Baxt B, Lubroth J, Mason PW: Vaccines Prepared from Chimeras of Foot-and-Mouth Disease Virus (FMDV) Induce Neutralizing Antibodies and Protective Immunity to Multiple Serotypes of FMDV. J Virol 1994, 68:7092-7098.

34. Samuel AR, Ouldridge EJ, Arrowsmith AE, Kitching RP, Knowles NJ: Antigenic analysis of serotype $\mathrm{O}$ foot-and-mouth disease virus isolates from the Middle East, 1981-1988. Vaccine 1990, 8:390-396.

35. Tsai CP, Pan CH, Liu MY, Lin YL, Chen CM, Huang TS, Cheng IC, Jong MH, Yang PC: Molecular epidemiological studies on foot-and-mouth disease type O Taiwan viruses from the 1997 epidemic. Vet Microbiol 2000, 74:207-216

36. Yang PC, Chu RM, Chung WB, Sung HT: Epidemiological characteristics and financial costs of the 1997 foot-and-mouth disease epidemic in Taiwan. Vet Rec 1999, 145:731-734.

37. Liu W, Wei MT, Tong Y, Tang F, Zhang L, Fang L, Yang H, Cao WC: Seroprevalence and genetic characteristics of five subtypes of influenza A viruses in the Chinese pig population: A pooled data analysis. Vet $J$ 2011, 187:200-206.

38. Baxt B, Vakharia V, Moore DM, Franke AJ, Morgan DO: Analysis of neutralizing antigenic sites on the surface of type $A 12$ foot-and-mouth disease virus. J Virol 1989, 63:2143-2151.

39. Stave JW, Card JL, Morgan DO, Vakharia VN: Neutralization sites of type 01 foot-and-mouth disease virus defined by monoclonal antibodies and neutralization-escape variants. Virology 1988, 149:21-29.

40. Bittle JL, Houghten RA, Alexander H, Shinnick TM, Sutcliffe JG, Lerner RA, Rowlands DJ, Brown F: Protection against foot-and-mouth disease by immunization with a chemically synthesized peptide predicted from the viral nucleotide sequence. Nature 1982, 298:30-33.

41. Di Marchi R, Brooke G, Gale C, Cracknell V, Doel T, Mowat N: Protection of cattle against foot-and-mouth disease by a synthetic peptide. Science 1986, 232:639-641

42. Grubman MJ, Baxt B: Foot-and-Mouth Disease. Clin Microbiol Rev 2004, 17:465-493.

43. Carrefio C, Roig X, Cairo J, Camarero J, Mateu MG, Domingo E, Giralt E, Andreu D: Studies on antigenic variability of $C$ strains of foot-and-mouth disease virus by means of synthetic peptides and monoclonal antibodies. Int J Pept Protein Res 1992, 39:41-47.

44. Martinez MA, Hernandez J, Piccone ME, Palma EL, Domingo E, Knowles N, Mateu MG: Two mechanisms of antigenic diversification of footand-mouth disease virus. Virology 1991, 184:695-706.

45. Mateu MG, Martinez MA, Capucci L, Andreu D, Giralt E, Sobrino F, Brocchi E, Domingo E: A single amino acid substitution affects multiple overlapping epitopes in the major antigenic site of foot-and-mouth disease virus of serotype C. J Gen Virol 1990, 71:629-637.

46. McKenna TS, Lubroth J, Rieder E, Baxt B, Mason PW: Receptor binding site deleted foot-and-mouth disease (FMD) virus protects cattle from FMD. J Virol 1995, 69:5787-5790.

47. Mateo R, Luna E, Rincon V, Mateu MG: Engineering viable foot-and-mouth disease viruses with increased thermostability as a step in the development of improved vaccines. J Virol 2008, 82:12232-12240.

48. Sa-Carvalho D, Rieder E, Baxt B, Rodarte R, Tanuri A: Tissue culture adaptation of foot-and-mouth disease virus selects viruses that bind to heparin and are attenuated in cattle. J Virol 1997, 71:5115-5123. 
49. Botner A, Kakker NK, Barbezange C, Berryman S, Jackson T, Belsham GJ: Capsid proteins from field strains of foot-and mouth disease virus confer a pathogenic phenotype in cattle on an attenuated, cell-culture-adapted virus. J Gen Virol 2011, 92:1141-1151.

50. Zhao Q, Pacheco J, Mason PW: Evaluation of genetically engineered derivatives of a Chinese strain of foot-and-mouth disease reveals a novel cell-binding site which functions in cell culture and in animals. J Virol 2003, 77:3269-3280.

51. Piatti P, Hassard S, Newman JFE, Brown F: Antigenic variants in a plaqueisolate of foot-and-mouth disease virus: implications for vaccine production. Vaccine 1995, 13:781-784.

doi:10.1186/1746-6148-8-57

Cite this article as: Li et al: Evaluation of a genetically modified foot-and-mouth disease virus vaccine candidate generated by reverse genetics. BMC Veterinary Research 2012 8:57.

\section{Submit your next manuscript to BioMed Central and take full advantage of:}

- Convenient online submission

- Thorough peer review

- No space constraints or color figure charges

- Immediate publication on acceptance

- Inclusion in PubMed, CAS, Scopus and Google Scholar

- Research which is freely available for redistribution 